\title{
Early outgrowth cells versus endothelial colony forming cells functions in platelet aggregation
}

\author{
Lara Bou Khzam 1,2, Olivier Bouchereau', Rahma Boulahya', Ahmed Hachem ', Younes Zaid',
} Haissam Abou-Saleh ${ }^{3}$ and Yahye Merhi ${ }^{1,4^{*}}$

\begin{abstract}
Background: Endothelial progenitor cells (EPCS) have been implicated in neoangiogenesis, endothelial repair and cell-based therapies for cardiovascular diseases. We have previously shown that the recruitment of EPCs to sites of vascular lesions is facilitated by platelets where EPCs, in turn, modulate platelet function and thrombosis. However, EPCs encompass a heterogeneous population of progenitor cells that may exert different effects on platelet function. Recent evidence suggests the existence of two EPC subtypes: early outgrowth cells (EOCs) and endothelial colonyforming cells (ECFCs). We aimed at characterizing these two EPC subtypes and at identifying their role in platelet aggregation.

Methods: EOCs and ECFCs were generated from human peripheral blood mononuclear cells (PBMCs) seeded in conditioned media on fibronectin and collagen, respectively. The morphological, phenotypical and functional characteristics of EOCs and ECFCs were assessed by optical and confocal laser scanning microscopes, cell surface markers expression, and Matrigel tube formation. The impact of EOCs and ECFCs on platelet aggregation was monitored in collagen-induced optical aggregometry and compared with PBMCs and human umbilical vein endothelial cells (HUVECs). The levels of the anti-platelet agents' nitric oxide $(\mathrm{NO})$ and prostacyclin $\left(\mathrm{PGI}_{2}\right)$ released from cultured cells as well as the expression of their respective producing enzymes NO synthases (NOS) and cyclooxygenases (COX) were also assessed.
\end{abstract}

Results: We showed that EOCs display a monocytic-like phenotype whereas ECFCs have an endothelial-like phenotype. We demonstrated that both EOCs and ECFCs and their supernatants inhibited platelet aggregation; however ECFCs were more efficient than EOCs. This could be related to the release of significantly higher amounts of $\mathrm{NO}$ and $\mathrm{PGI}_{2}$ from ECFCs, in comparison to EOCs. Indeed, ECFCs, like HUVECs, constitutively express the endothelial (eNOS) and inducible (iNOS) - NOS isoforms, and COX-1 and weakly express COX-2, whereas EOCs do not constitutively express these $\mathrm{NO}$ and $\mathrm{PGI}_{2}$ producing enzymes.

Conclusion: The different morphological, phenotypic and more importantly the release of the anti-aggregating agents $\mathrm{PGI}_{2}$ and $\mathrm{NO}$ in each EPC subtype are implicated in their respective roles in platelet function and thus, may be linked to the increased efficiency of ECFCs in inhibiting platelet aggregation as compared to EOCs.

Keywords: Endothelial progenitor cells, Platelets, Aggregation, Prostacyclin, Nitric oxide

\footnotetext{
*Correspondence: yahye.merhi@icm-mhi.org

${ }^{1}$ Laboratory of Thrombosis and Hemostasis, Montreal Heart Institute,

5000 Belanger, Montreal, QC H1T 1C8, Canada

Full list of author information is available at the end of the article
} 


\section{Background}

Endothelial progenitor cells (EPCs) are believed to play a significant role in vascular biology through their implication in vascular repair, cell therapy, and regenerative medicine [1-4]. Definitive proof of the existence of circulating EPCs was provided in 1997 [5], showing that human peripheral blood contains $\mathrm{CD}_{3} 4^{+}$and vascular endothelial growth factor receptor $2^{+}\left(\mathrm{VEGFR}^{+}\right)$progenitor cells, which can attach to fibronectin, acquire certain characteristics of mature endothelial cells (ECs) in vitro, and contribute to neoangiogenesis in vivo. Since then, numerous cells have been employed to improve cardiovascular function, including EPCs, bone marrow mononuclear cells, myocardial stem cells, mesenchymal stem cells, and embryonic stem cells [6, 7]. Among these, EPCs have emerged as important modulators in vascular biology and hemostasis. However, controversies still exist as to their therapeutic and diagnostic use [8-10]. One important aspect of EPC biology is their interaction with vascular and blood cells, which can largely influence their functional properties. More specifically, the interaction of EPCs with platelets provides the critical signal to ensure their migration and homing at sites of vascular injury and their differentiation into ECs [11-17]. Conversely, EPCs affect platelet function [18-22] and modulate endothelial repair [23-27], which add new insights to the importance of EPCs in vascular hemostasis.

In our attempt to elucidate the functional importance of EPC interactions with platelets, we have previously shown that a heterogeneous population of EPCs, derived from PBMCs after 10 days of culture, modulates the function of platelets [18], through binding to platelets via P-selectin [28]. This interaction impairs the function of platelets through an increase in cyclooxygenase-2 (COX-2) expression and prostacyclin $\left(\mathrm{PGI}_{2}\right)$ release. Recent experimental evidence has established that cells originally defined as EPCs and used for potential therapy are not true endothelial progenitors [8, 29-31]. Indeed, recent analyses have revealed that, depending on how EPCs are isolated and cultured, the EPC population can either consist of a minimally proliferative myeloidmonocytic cell population (early EPCs, monocytic EPCs, EOCs, or cultured angiogenic cells) or consist primarily of a highly proliferative non-myeloid EC population (late EPCs, ECFCs, or late outgrowth cells) [9, 32-34]. In this regard, we have been characterizing and studying the well-defined EOC subtype and showed that they produce matrix metalloproteinase- 9 and reactive oxygen species that influence their pro-angiogenic [23] and anti-platelet functions [19], respectively. On the other hand, ECFCs are considered highly proliferative cells that incorporate at sites of vascular lesions, differentiate into ECs and contribute to endothelial repair [9, 32, 33, 35]. Their anti-platelet properties could be of great importance in vascular hemostasis and repair. Accordingly, this study was designed to describe the characteristics of EOCs and ECFCs, and to compare their effect on platelet function by defining the underlying vasoactive substances implicated in this process. The major findings are that ECFCs are more efficient in inhibiting platelet aggregation than EOCs. This was related to an increase in the production of the potent anti-platelet agents $\mathrm{PGI}_{2}$ and $\mathrm{NO}$ by ECFCs, which induce significantly stronger inhibitory effects of platelet aggregation.

\section{Methods}

\section{Culture and characterization of human EOCs and ECFCs}

This study was carried out according to a protocol accepted by the Montreal Heart Institute ethical committee in agreement with the Declaration of Helsinki. Informed consent was obtained from healthy volunteers aged between 20 and 60 years and medication free over 10 days prior to blood sampling. Ficoll-Paque (GE Healthcare, Piscataway, NJ, USA) density gradient centrifugation was used to isolate peripheral blood mononuclear cells (PBMCs) from $100 \mathrm{~mL}$ of peripheral blood, as previously described [18]. To generate EOCs, $1 \times 10^{6}$ PBMCs per $\mathrm{cm}^{2}$ were seeded on 6-well fibronectincoated tissue culture plates (BD Biosciences, Mississauga, $\mathrm{ON}$, Canada) in complete endothelial growth media EGM-2 (Lonza Inc., Burlington, ON, Canada) at $37^{\circ} \mathrm{C}$ in an atmosphere of $5 \% \mathrm{CO}_{2}$. Following 3 days of culture, the medium was changed to remove non-adherent cells. Additional culturing of adherent cells up to 7 days was allowed to obtain EOCs [23, 36]. ECFCs were generated from PBMCs seeded at a density of $5 \times 10^{6}$ mononuclear cells per $\mathrm{cm}^{2}$ in 6-well collagen-coated tissue culture plates (BD Biosciences). Culturing of ECFCs was performed in EGM-2 supplemented with $10 \%$ FBS. The medium was changed daily for 7 days and every other day thereafter until the appearance of endothelial cell colonies (2-4 weeks), which were cultured until the formation of a confluent monolayer of highly proliferative EPCs [36-38]. Cells were used between passages three and six. Characterization of EOCs and ECFCs was compared to mature human umbilical vein endothelial cells (HUVECs) (Lonza Inc.) cultured in complete EGM2 with $10 \%$ FBS on $0.2 \%$ gelatin-coated flasks.

\section{Confocal microscopy}

EOCs and ECFCs were incubated with DiI-labeled acetylated low density lipoprotein (DiI-Ac-LDL) (Invitrogen, Carlsbad, CA, USA) for $2 \mathrm{~h}$ followed by $4 \%$ paraformaldehyde fixation and subsequent 1-hour incubation with FITC-labeled Ulex-lectin (Sigma-Aldrich, St-Louis, MO, USA). Nuclear staining was done with TO-PRO-3 
(Invitrogen). Cells were visualized under an LSM 510 confocal microscope (Zeiss, Oberkochen, Germany) at $63 \times$ objective magnification [18].

\section{Matrigel tube formation assay}

EPC's potential to form tube-like structures was compared to that of HUVECs on Matrigel-coated 24-well plates [39]. Growth factor reduced Matrigel (BD Biosciences) $(200 \mu \mathrm{L})$ was incubated for $30 \mathrm{~min}$ at $37{ }^{\circ} \mathrm{C}$ in a $5 \% \mathrm{CO}_{2}$ atmosphere to allow polymerization and formation of a gel-like surface. Cells were harvested with trypsin-EDTA $0.05 \%$ (Gibco, Burlington, ON, Canada), washed and resuspended in complete EGM-2 at $200 \times 10^{3}$ per $300 \mu \mathrm{L}$ per well. Following 24 -h incubation at $37{ }^{\circ} \mathrm{C}$ in a $5 \% \mathrm{CO}_{2}$ atmosphere, cells were viewed under an inverted microscope and images were taken at $10 \times$ objective magnification.

\section{Cell surface marker expression}

Phenotypic characterization of EOCs and ECFCs was performed by flow cytometry and compared to PBMCs and HUVECs [18]. Cells were harvested by washing cells with phenol red-free and serum-free basal RPMI 1640 medium followed by trypsinization with $0.05 \%$ trypsin-EDTA (Gibco) for $15 \mathrm{~min}$ at $37{ }^{\circ} \mathrm{C}$ [38]. Cells were subsequently blocked with normal mouse serum for $15 \mathrm{~min}$, washed and incubated for $30 \mathrm{~min}$ with PElabeled fluorescent human monoclonal antibodies against the monocytic marker CD14 (R\&D Systems, Minneapolis, MN, USA), the leukocytic marker CD45 (AbD Serotec, Oxford, UK), the progenitor marker CD34 (BD Biosciences), the angiogenic marker VEGFR2 (R\&D Systems), and the endothelial markers CD31 (BD Biosciences) and CD144 (BD Biosciences). Cells were then fixed with paraformaldehyde for $30 \mathrm{~min}$ and analyzed on an Altra flow cytometer (Beckman Coulter, Mississauga, ON, Canada). Cells were gated by their characteristic forward and side scatter properties.

\section{Platelet aggregation}

Platelets were isolated from $100 \mathrm{~mL}$ peripheral blood of healthy volunteers, as previously described $[18,19]$. Washed platelets resuspended in HBSS-Hank's buffer were then adjusted to $250 \times 10^{6} / \mathrm{mL}$. Platelet aggregation was performed in a four-channel optical aggregometer (Chronolog Corp., Havertown, PA, USA) under shear $(1000 \mathrm{rpm})$ at $37^{\circ} \mathrm{C}$. A volume of $400 \mu \mathrm{L}$ of the washed platelet preparation was incubated with $100 \mu \mathrm{L}$ of PBMC, EOC, and ECFC cells or their supernatants at $37{ }^{\circ} \mathrm{C}$ for $5 \mathrm{~min}$ prior to the assay. Platelet aggregation was then induced with $1 \mu \mathrm{g} / \mathrm{mL}$ collagen (Chronolog Corp.), and traces were recorded until stabilization of platelet aggregation was reached. Controls were performed by incubating platelets with complete EGM-2 culture medium.

\section{Western blot}

EOCs and ECFCs were harvested using trypsin-EDTA $0.05 \%$ (Gibco), centrifuged at $500 \times g$ for $10 \mathrm{~min}$ then resuspended in PBS $1 \times$ and sonicated. Protein content was assessed by the Bradford assay method, mixed with the appropriated volume of $4 \times$ Laemmli loading buffer and heated for $5 \mathrm{~min}$ at $95{ }^{\circ} \mathrm{C}$. Protein lysates $(40 \mu \mathrm{g})$ were resolved by SDS-PAGE and transferred onto nitrocellulose membranes (Bio-Rad, Hercules, CA, USA). Membranes were blocked with $5 \%$ non-fat milk in TBSTween-20 for $1 \mathrm{~h}$. Membranes were then incubated overnight with primary antibodies (1:1000) against eNOS and iNOS (Cell Signaling, Beverly, MA, USA), and against COX-1 and COX-2 (Santa Cruz Biotechnology, Santa Cruz, CA, USA). Following washing steps, membranes were labeled with horseradish peroxidase-conjugated secondary antibody for $1 \mathrm{~h}$, washed and bound peroxidase activity was detected by enhanced chemiluminescence (Perkin Elmer Life Sciences, Waltham, MA, USA).

\section{$\mathrm{PGl}_{2}$ release assay}

A commercial radioimmunoassay (RIA) $\mathrm{PGI}_{2}$ kit was used to assess prostacyclin release (Assay Designs, San Diego, CA, USA) according to manufacturer instructions. Levels of 6-keto-PGF ${ }_{1 \propto}$, the stable metabolite of $\mathrm{PGI}_{2}$, were assessed in EOC and ECFC culture supernatants and compared to PBMC and HUVEC supernatants.

\section{NO release assay}

A commercial fluorometric $\mathrm{NO}$ assay kit was used to assess nitric oxide release (Cayman Chemicals, Ann Arbor, MI, USA) according to manufacturer instructions. Levels of total nitrate and nitrite $\left(\mathrm{NO}_{2}{ }^{-}\right.$and $\left.\mathrm{NO}_{3}{ }^{-}\right)$were assessed in EOC and ECFC supernatants and net nitrate $\left(\mathrm{NO}_{2}{ }^{-}\right)$concentrations were calculated and compared to PBMC and HUVEC supernatants.

\section{Statistical analysis}

Results are presented as mean \pm SEM of at least three independent experiments. Statistical comparisons were done using either paired student's $t$ test or a one-way ANOVA followed by a Dunnett's- $t$-test for comparison against a single group. Data with $p<0.05$ were considered statistically significant.

\section{Results}

EOCs and ECFCs are morphologically and phenotypically different

Different culture techniques were required to generate each EPC subtype. EOCs were generated from PBMCs 
cultured for 7 days on fibronectin-coated plates whereas ECFCs were obtained following longer culture periods (2-4 weeks) on collagen-coated plates. The morphology observed for each cell subtype differs greatly. EOCs form a heterogeneous population of round and elongated cells whereas ECFCs form a cobblestone-like monolayer of homogenous appearance (Fig. 1a). EOCs display an immature endothelial cell character since they still resemble the PBMC population from which they derive following 7 days of culture. On the other hand, ECFCs seem to acquire an endothelial-like phenotype resembling HUVECs. Furthermore, EOCs are short-lived cells which do not survive past 7 days whereas ECFCs are highly proliferative cells which can be passaged and kept in culture for months (data not shown). Both EOCs and ECFCs bind Ulex-lectin and internalize DiI-Ac-LDL, both endothelial cell characteristics (Fig. 1b).

\section{EOCs and ECFC tube formation potential}

We show that EOCs and ECFCs are also functionally different. EOCs do not form tube-like structures, whereas ECFCs, similarly to HUVECs, form well-structured tubes on Matrigel (Fig. 1c).

\section{EOCs and ECFC cell surface marker expression}

EOCs continue to express the leukocytic and monocytic cell surface markers CD45 and CD14, respectively, after 7 days of culture, whereas ECFCs lose these markers throughout their differentiation process. Moreover, EOCs strongly express the angiogenic marker VEGFR2. Unlike EOCs, ECFCs express the progenitor cell marker CD34 and the endothelial cell marker CD144. All cell populations showed uniform expression of the platelet-endothelial cell adhesion molecule CD31 (Fig. 2).

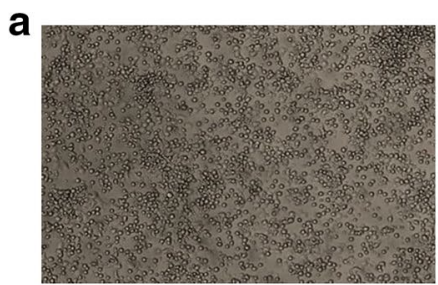

PBMCs

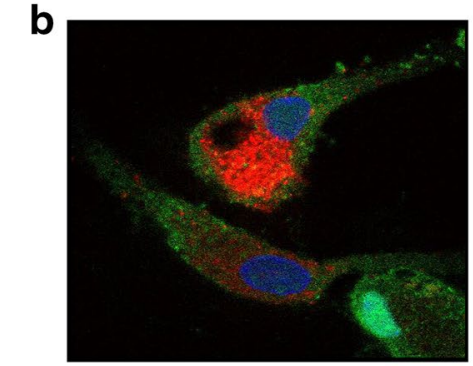

EOCs

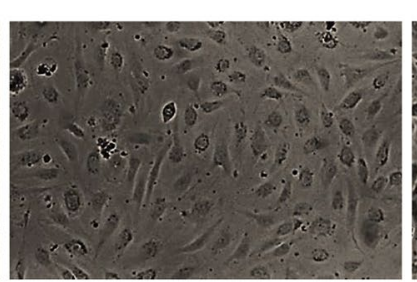

ECFCs

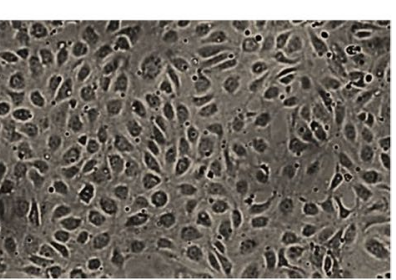

HUVECs

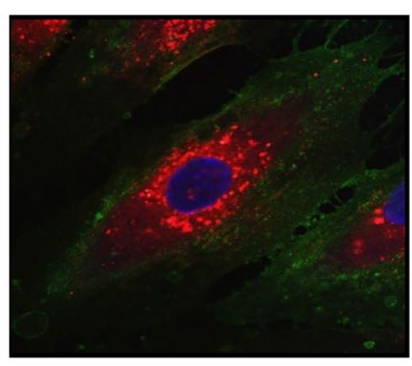

ECFCs

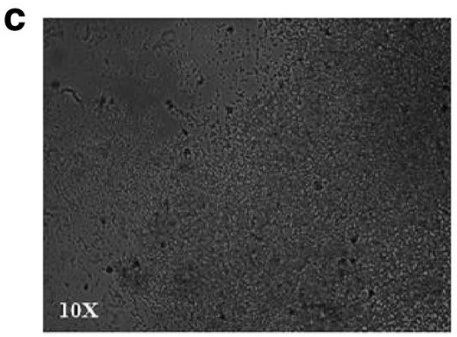

EOCs

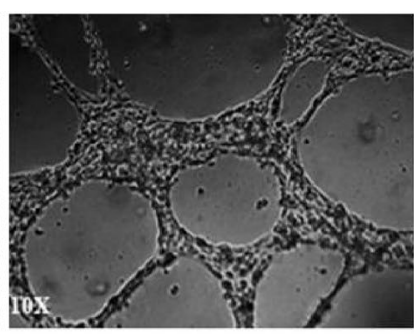

ECFCs

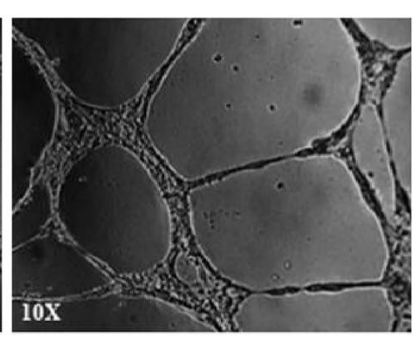

HUVECs

Fig. 1 Characterization of PBMC-derived EOCs and ECFCs. a Representative optical microscopy images of EOCs and ECFCs taken at 10× magnification using an inverted light microscope. EOCs display a heterogeneous population of round and elongated cells on fibronectin following 7 days of culture. ECFCs show a homogeneous population forming a cobblestone-like monolayer on collagen following 21 days of culture. b Representative confocal microscopy images showing EOCs and ECFCs triple staining for Dil-Ac-LDL uptake (red), Ulex-lectin binding (green) and TO-PRO-3 nuclear staining (blue) taken at $63 \times$ magnification. c Representative optical microscopy images showing the tube-like structure formation potential of EOCs and ECFCs compared to HUVECs on a Matrigel surface taken at 10x magnification using an inverted microscope 


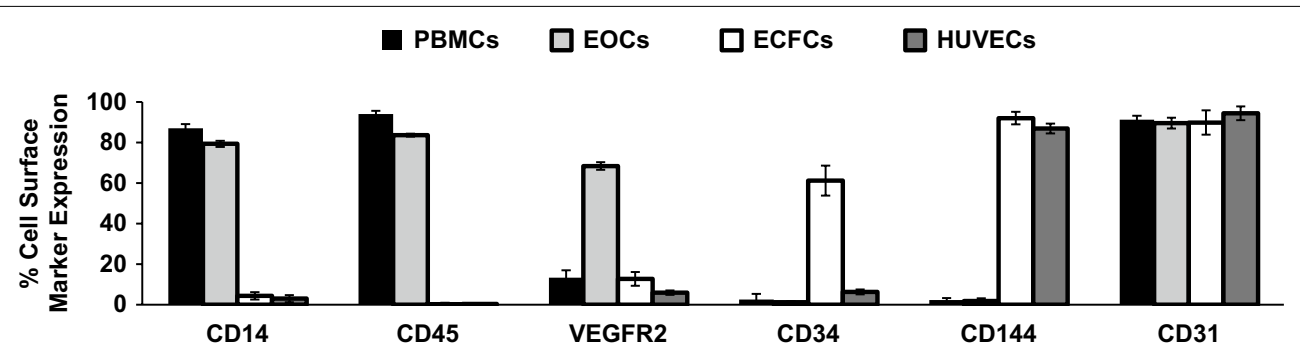

Fig. 2 Expression of cell surface markers by EOCs and ECFCs. Flow cytometric analysis of cell surface marker expression profile of EOCs (gray) and ECFCs (white) compared to PBMCs (black) and HUVECs (dark gray) using mouse anti-human PE-conjugated monoclonal antibodies against CD14, CD45, VEGFR2, CD34, CD144 and CD31. Histogram represents the mean data \pm SEM of percent cell surface marker expression $(n \geq 3)$

EOCs and ECFCs inhibit platelet aggregation

In order to better understand the influence of EPCs on platelets, we sought to investigate the effect of each EPC subtype on platelet aggregation. We show that both
EOCs and ECFCs and their respective supernatants inhibit platelet aggregation, in comparison to PBMCs (Fig. 3). However, we noticed an increased efficiency of the supernatants in inhibiting platelet aggregation in



b

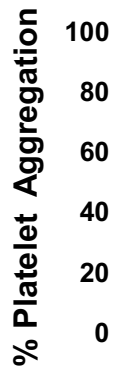

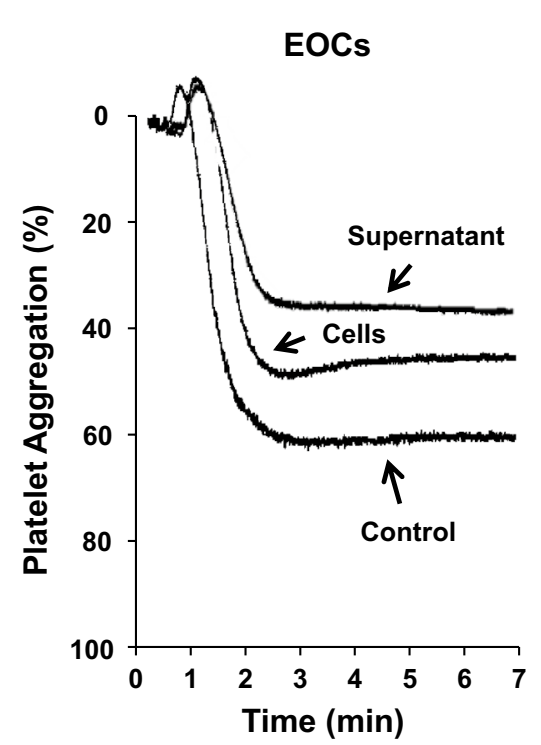

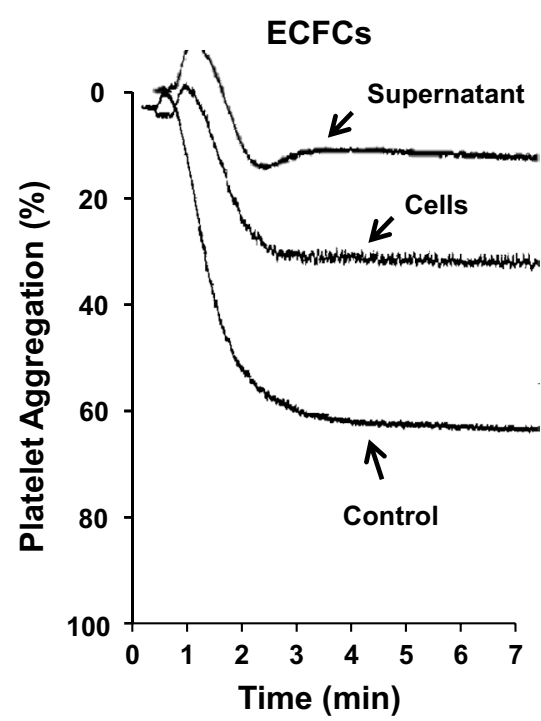

- Supernatant

Cells

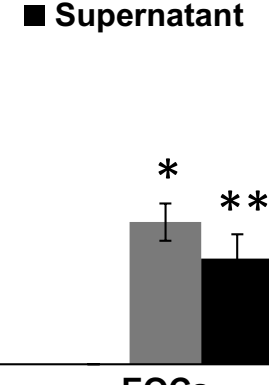

EOCs

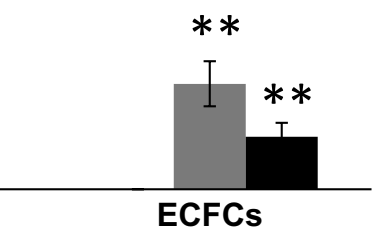

Fig. 3 Effect of PBMCs, EOCs and ECFCs on platelet aggregation. a Representative traces of platelet aggregation. Platelets were incubated with complete EGM-2 medium (control) or in the presence of $4 \times 10^{6} / \mathrm{mL}$ PBMC, EOC and ECFC cells or their respective supernatants for $5 \mathrm{~min}$ at $37^{\circ} \mathrm{C}$ prior to aggregation initiation with $1 \mu \mathrm{g} / \mathrm{mL}$ of collagen. $\mathbf{b}$ Histogram represents the mean data of percent platelet aggregation $\pm \operatorname{SEM}(n \geq 3$, ** $p<0.01$ vs control) 
comparison to their respective cell samples for both EOCs and ECFCs. We suggest that this may be due to the release of vasoactive agents which play an important role in platelet aggregation. Furthermore, we demonstrated that ECFCs are more efficient at inhibiting platelet aggregation than EOCs.

\section{ECFCs release more $\mathrm{NO}$ and $\mathrm{PGl}_{2}$ than EOCs}

To further understand the increased efficiency of ECFCs compared to EOCs in inhibiting platelet aggregation, we compared the NOS and COX expression profiles in EOCs, ECFCs, PBMCs, and HUVECs. We found that ECFCs, similarly to HUVECs, constitutively express eNOS, iNOS, and COX-1, but to a lesser extent COX2. In contrast, EOCs do not constitutively express these $\mathrm{NO}$ and $\mathrm{PGI}_{2}$ producing enzymes (Fig. 4a). Using radioimmunoassay and fluorometric techniques, we assessed $\mathrm{PGI}_{2}$ and NO release, respectively. We found that EOCs release minimal amounts of $\mathrm{NO}(60 \mathrm{pmol})$ and $\mathrm{PGI}_{2}$ $(300 \mathrm{pg} / \mathrm{mL})$ whereas ECFCs, similarly to HUVECs, release significantly higher levels of both NO (90 pmol) and $\mathrm{PGI}_{2}(5000 \mathrm{pg} / \mathrm{mL})$ (Fig. $\left.4 \mathrm{~b}, \mathrm{c}\right)$. The higher expression of NOS and COX enzymes in ECFCs account for the significantly higher levels of $\mathrm{NO}$ and $\mathrm{PGI}_{2}$ released by these cells in comparison to EOCs.

\section{Discussion}

EPCs have gained much attention in the past decade for their therapeutic role; however, no clear consensus has been achieved to date as to the origin and specific function of these cells. Indeed, the term EPCs represents a complex assortment of progenitor cells that play different role on neoangiogenesis and vascular repair. The characterization and critical re-evaluation of EPC phenotypes are therefore essential for their efficiency as therapeutic and diagnostic tools (for review Fadini et al. [9]). Different conditions such as source, media, incubation times and culture surfaces have yielded different subtypes of EPCs. However, recent evidence suggests the existence of two subtypes of EPCs according to their time-dependent

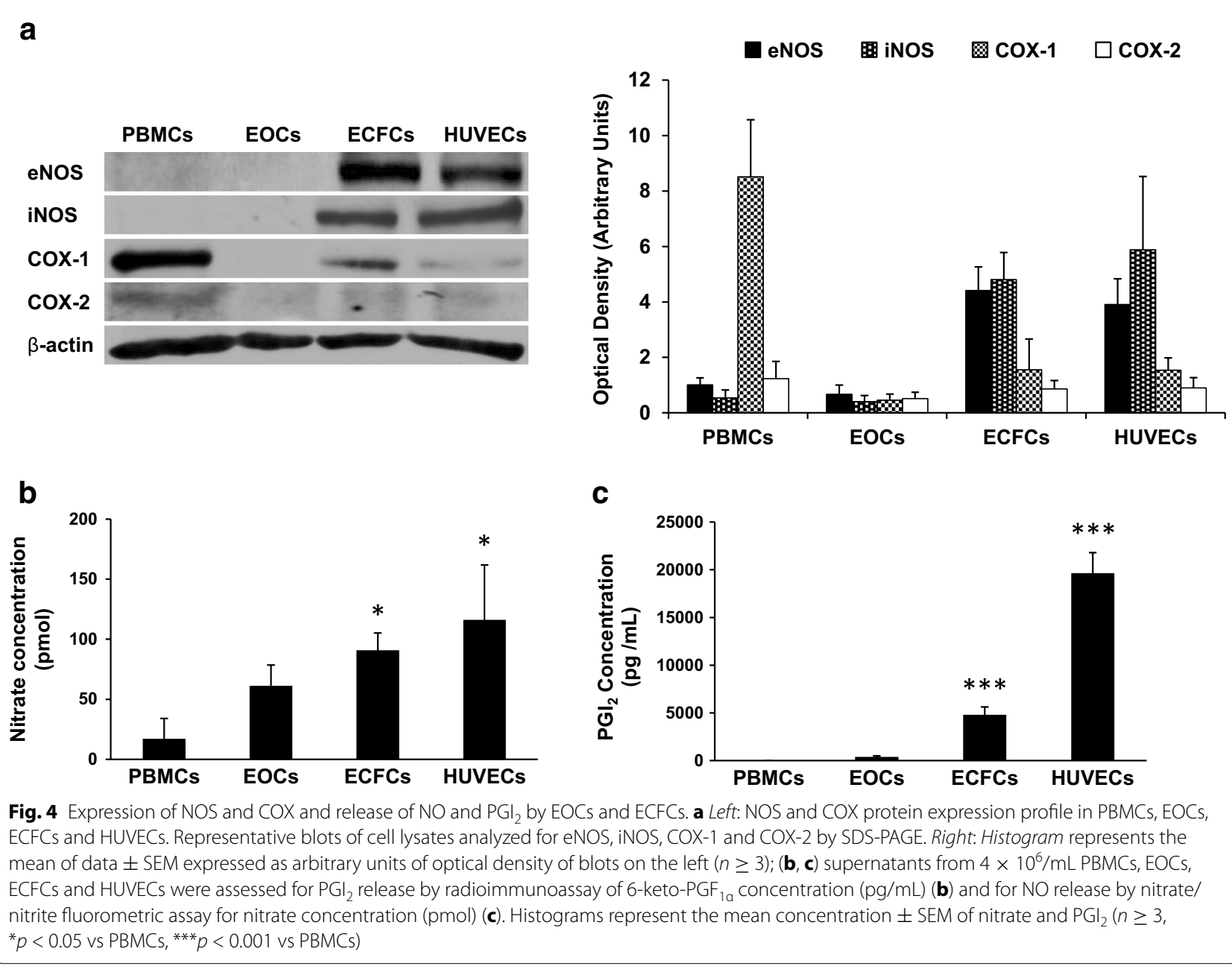


appearance. Based on new findings and on standardized isolation and differentiation protocols [30, 34, 36-38], we have first successfully differentiated two subtypes of EPCs from PBMCs: EOCs and ECFCs, each distinct in their morphology, phenotype, and function. As it has previously been argued, we have found that EOCs and ECFCs differ in morphology and phenotype since EOCs possess monocytic-like characteristics, whereas ECFCs are rather endothelial-like cells. In addition, EOCs neither proliferate nor form tube-like structures, whereas ECFCs are highly proliferative and form structured and defined tubes on Matrigel. These data confirm previous studies showing that EOCs lack the ability to incorporate into the neovasculature, but rather influence neovascularization through the release of paracrine factors, whereas ECFCs can be incorporated in new vessel formation $[36,40]$. However, the two EPC subtypes seem to act synergistically in vascular repair [40-42]. Therefore, we aimed at studying the role of EOCs and ECFCs in platelet function as the former cannot form new vessels but may considerably influence platelets by releasing a multitude of vasoactive substances, whereas the latter may indirectly influence platelet function while incorporating at sites of vascular lesions.

EPCs and platelet interactions occur at sites of vascular lesions in order to promote vascular repair. Being the first cells to be recruited at sites of vascular damage, platelets become activated to release a multitude of paracrine factors (SDF-1) and to express cell surface adhesion molecules (P-selectin), which allow for the recruitment and differentiation of EPCs $[14,15,43]$. In turn, EPCs also modulate the function of platelets by releasing paracrine factors $[18,19]$, such as $\mathrm{PGI}_{2}$ and $\mathrm{NO}$, which are the two main endothelium-derived vasodilation substances that display potent anti-platelet properties [44]. In the present study, we showed that both EOCs and ECFCs inhibit platelet aggregation. However, ECFCs are significantly more efficient than EOCs at inhibiting this process. Interestingly, the supernatants from both EOCs and ECFCs inhibit platelet aggregation more efficiently than their respective cells. Next, we compared the levels of $\mathrm{PGI}_{2}$ and NO released by EOCs and ECFCs, as these two substances are the major endothelium-derived vasodilation agents that play protective and antithrombotic roles in platelet reactivity. We showed that EOCs release smaller quantities of both $\mathrm{PGI}_{2}$ and $\mathrm{NO}$ in comparison to ECFCs. This could be related to the presence of a higher quantity of $\mathrm{NO}$ and $\mathrm{PGI}_{2}$ in the supernatants, which accounts for their increased efficiency in inhibiting platelet function as compared to the cells. In this connection, COX-1 and COX-2 are the enzymes involved in the production of prostaglandins, thromboxane and $\mathrm{PGI}_{2}$. Nitric oxide synthases (eNOS, iNOS and nNOS) are the enzymes involved in NO production, among which eNOS and iNOS are mainly responsible for NO production by the endothelium. Different levels of expression and regulation of the COX and NOS enzymes determine the levels of $\mathrm{PGI}_{2}$ and $\mathrm{NO}$ released by different vascular cell types. Interestingly, we found that ECFCs, similarly to HUVECs, constitutively express eNOS, iNOS and COX-1, but to a lesser extent COX-2. Surprisingly, EOCs do not constitutively express these $\mathrm{NO}$ and $\mathrm{PGI}_{2}$ producing enzymes. This could be related in part to a regulatory mechanism that occurs at this early stage of the differentiation process, where EOCs, like other $\mathrm{NO}$ and $\mathrm{PGI}_{2}$ producing cells, need to be triggered to upregulate COX and NOS enzymes. However, further investigation is needed to clarify this issue. In the other hand, the pattern expression of COX and NOS in our ECFC population was close to those found in EPCs generated in our previous study [18]. This could explain why ECFCs release considerably higher amounts of the anti-aggregating agents $\mathrm{PGI}_{2}$ and NO than EOCs, thereby accounting for their enhanced capacity in inhibiting platelet aggregation. However, the mechanism by which EOCs and their supernatants inhibit platelet aggregation remains to be determined. In addition, further research is required to understand the intracellular mechanisms underlying the differential influence of EOCs and ECFCs on platelet function.

\section{Conclusions}

Endothelial progenitor cells are regarded as promising therapeutic tools for vascular repair, tissue engineering, and regenerative medicine. However, the clinical usefulness of these cells is hindered by the existence of diverse subtypes of EPCs which exert diverse therapeutic potential. EPCs generated from the culture of PBMCs have been identified as EOCs and ECFCs depending on the culture conditions. In this study, we determined the characteristics of EOCs and ECFCs, and we defined their impact on platelet aggregation, the essential function in both vascular injury and vascular repair. We found that EOCs and ECFCs display distinct morphological, phenotypical, and functional characteristics. In addition, we demonstrated that both EOCs and ECFCs inhibit platelet aggregation, however; the inhibitory effect of ECFCs was more pronounced than EOCs. These inhibitory effects seem to be mediated by the secretion of the anti-aggregating agents $\mathrm{PGI}_{2}$ and $\mathrm{NO}$ by EOCs and, to a greater extent by ECFCs, thus accounting for their enhanced capacity in inhibiting platelet aggregation. These findings enforce our current understandings of different subsets of EPCs and provide novel insights into the differential role played by EOCs and ECFCs in modulating platelet function during vascular repair. This knowledge would benefit the management of atherothrombosis 
during acute coronary syndromes and following percutaneous coronary interventions. Ultimately, this may lead to the development of novel strategies for EPC-derived antithrombotic therapies and vascular regeneration in patients with cardiovascular disease.

\begin{abstract}
Abbreviations
EPCs: endothelial progenitor cells; ECs: endothelial cells; EOCs: early outgrowth cells; ECECs: endothelial colony forming cells; PBMCs: peripheral blood mononuclear cells; HUVECs: human umbilical vein endothelial cells; VEGFR2: vascular endothelial growth factor receptor 2; $\mathrm{PGI}_{2}$ : prostacyclin; $\mathrm{NO}$ : nitric oxide; $\mathrm{COX}$ : cyclooxygenase; eNOS: endothelial nitric oxide synthase; iNOS: inducible nitric oxide synthase.
\end{abstract}

\section{Authors' contributions}

LBK designed the study, performed the experiments, acquired and interpreted the data, and drafted the manuscript. OB contributed to EPC isolation and western blot experiments. RB participated in platelet isolation and aggregation, and provided technical support. AH participated in platelet isolation and flow cytometry experiments and revised the manuscript. HAS participated in manuscript preparation and revision, provided technical support, and drafted the manuscript. YM conceived and designed the study, evaluated data, and drafted the manuscript. All authors read and approved the final manuscript.

\section{Author details}

${ }^{1}$ Laboratory of Thrombosis and Hemostasis, Montreal Heart Institute, 5000 Belanger, Montreal, QC H1T 1C8, Canada. ${ }^{2}$ Department of Biochemistry, Weill Cornell Medical College in Qatar, Doha, Qatar. ${ }^{3}$ Division of Cardiology, Sidra Medical and Research Center, Doha, Qatar. ${ }^{4}$ Faculty of Medicine, Université de Montréal, Montreal, QC, Canada.

\section{Acknowledgements}

This study was supported by grants from the Canadian Institute for Health Research and the Heart and Stroke Foundation of Canada. We thank Mr. Louis Villeneuve for his technical assistance with confocal microscopy imaging and Dr. Daniel Yacoub for his help in editing the manuscript.

\section{Competing interests}

The authors declare that they have no competing interests.

Received: 26 June 2015 Accepted: 2 November 2015 Published online: 09 November 2015

\section{References}

1. Wassmann S, Werner N, Czech T, Nickenig G. Improvement of endothelial function by systemic transfusion of vascular progenitor cells. Circ Res. 2006;99(8):e74-83.

2. Larsen K, Cheng C, Tempel D, Parker S, Yazdani S, den Dekker WK, Houtgraaf JH, de Jong R, Swager-ten Hoor S, Ligtenberg E, et al. Capture of circulatory endothelial progenitor cells and accelerated re-endothelialization of a bio-engineered stent in human exvivo shunt and rabbit denudation model. Eur Heart J. 2012;33(1):120-8.

3. Kong D, Melo LG, Gnecchi M, Zhang L, Mostoslavsky G, Liew CC, Pratt RE, Dzau VJ. Cytokine-induced mobilization of circulating endothelial progenitor cells enhances repair of injured arteries. Circulation. 2004;110(14):2039-46.

4. Griese DP, Ehsan A, Melo LG, Kong D, Zhang L, Mann MJ, Pratt RE, Mulligan RC, Dzau VJ. Isolation and transplantation of autologous circulating endothelial cells into denuded vessels and prosthetic grafts: implications for cell-based vascular therapy. Circulation. 2003;108(21):2710-5.

5. Asahara T, Murohara T, Sullivan A, Silver M, van der Zee R, Li T, Witzenbichler B, Schatteman G, Isner JM. Isolation of putative progenitor endothelial cells for angiogenesis. Science. 1997;275(5302):964-7.

6. Sieveking DP, Ng MK. Cell therapies for therapeutic angiogenesis: back to the bench. Vasc Med. 2009;14(2):153-66.
7. Dixit P, Katare R. Challenges in identifying the best source of stem cells for cardiac regeneration therapy. Stem Cell Res Ther. 2015;6:26.

8. Pearson JD. Endothelial progenitor cells-hype or hope? J Thromb Haemost. 2009;7(2):255-62.

9. Fadini GP, Losordo D, Dimmeler S. Critical reevaluation of endothelial progenitor cell phenotypes for therapeutic and diagnostic use. Circ Res. 2012;110(4):624-37.

10. Tura O, Skinner EM, Barclay GR, Samuel K, Gallagher RC, Brittan M, Hadoke PW, Newby DE, Turner ML, Mills NL. Late outgrowth endothelial cells resemble mature endothelial cells and are not derived from bone marrow. Stem Cells. 2013;31(2):338-48.

11. Daub K, Langer H, Seizer P, Stellos K, May AE, Goyal P, Bigalke B, Schonberger T, Geisler T, Siegel-Axel D, et al. Platelets induce differentiation of human CD34 + progenitor cells into foam cells and endothelial cells. FASEB J. 2006;20(14):2559-61.

12. de Boer HC, Verseyden C, Ulfman LH, Zwaginga JJ, Bot I, Biessen EA, Rabelink TJ, van Zonneveld AJ. Fibrin and activated platelets cooperatively guide stem cells to a vascular injury and promote differentiation towards an endothelial cell phenotype. Arterioscler Thromb Vasc Biol. 2006;26(7):1653-9.

13. Lev El, Estrov Z, Aboulfatova K, Harris D, Granada JF, Alviar C, Kleiman NS, Dong JF. Potential role of activated platelets in homing of human endothelial progenitor cells to subendothelial matrix. Thromb Haemost. 2006;96(4):498-504.

14. Massberg S, Konrad I, Schurzinger K, Lorenz M, Schneider S, ZohInhoefer D, Hoppe K, Schiemann M, Kennerknecht E, Sauer S, et al. Platelets secrete stromal cell-derived factor 1 alpha and recruit bone marrow-derived progenitor cells to arterial thrombi invivo. J Exp Med. 2006;203(5):1221-33.

15. Stellos K, Langer H, Daub K, Schoenberger T, Gauss A, Geisler T, Bigalke B, Mueller I, Schumm M, Schaefer I, et al. Platelet-derived stromal cell-derived factor-1 regulates adhesion and promotes differentiation of human CD34 + cells to endothelial progenitor cells. Circulation. 2008;117(2):206-15

16. Feng W, Madajka M, Kerr BA, Mahabeleshwar GH, Whiteheart SW, Byzova TV. A novel role for platelet secretion in angiogenesis: mediating bone marrow-derived cell mobilization and homing. Blood. 2011;117(14):3893-902.

17. Raz O, Lev DL, Battler A, Lev El. Pathways mediating the interaction between endothelial progenitor cells (EPCS) and platelets. PLOS ONE. 2014;9(6):e95156.

18. Abou-Saleh H, Yacoub D, Theoret JF, Gillis MA, Neagoe PE, Labarthe B, Theroux P, Sirois MG, Tabrizian M, Thorin E, et al. Endothelial progenitor cells bind and inhibit platelet function and thrombus formation. Circulation. 2009:120(22):2230-9.

19. Bou Khzam L, Hachem A, Zaid Y, Boulahya R, Mourad W, Merhi Y. Soluble CD40 ligand impairs the anti-platelet function of peripheral blood angiogenic outgrowth cells via increased production of reactive oxygen species. Thromb Haemost. 2013;109(5):940-7.

20. Shirota T, He H, Yasui H, Matsuda T. Human endothelial progenitor cell-seeded hybrid graft: proliferative and antithrombogenic potentials in vitro and fabrication processing. Tissue Eng. 2003;9(1):127-36.

21. Li XQ, Meng QY, Wu HR. Effects of bone marrow-derived endothelial progenitor cell transplantation on vein microenvironment in a rat model of chronic thrombosis. Chin Med J. 2007;120(24):2245-9.

22. Alexandru N, Popov D, Dragan E, Andrei E, Georgescu A. Circulating endothelial progenitor cell and platelet microparticle impact on platelet activation in hypertension associated with hypercholesterolemia. PLoS ONE. 2013;8(1):e52058.

23. Bou Khzam L, Boulahya R, Abou-Saleh H, Hachem A, Zaid Y, Merhi Y. Soluble CD40 ligand stimulates the pro-angiogenic function of peripheral blood angiogenic outgrowth cells via increased release of matrix metalloproteinase-9. PLoS ONE. 2013;8(12):e84289.

24. Aoki J, Serruys PW, van Beusekom H, Ong AT, McFadden EP, Sianos G, van der Giessen WJ, Regar E, de Feyter PJ, Davis HR, et al. Endothelial progenitor cell capture by stents coated with antibody against CD34: the HEALING-FIM (healthy endothelial accelerated lining inhibits neointimal growth-first in man) Registry. J Am Coll Cardiol. 2005;45(10):1574-9.

25. Kaushal S, Amiel GE, Guleserian KJ, Shapira OM, PerryT, Sutherland FW, Rabkin E, Moran AM, Schoen FJ, Atala A, et al. Functional small-diameter neovessels created using endothelial progenitor cells expanded ex vivo. Nat Med. 2001;7(9):1035-40. 
26. Shirota T, Yasui H, Shimokawa H, Matsuda T. Fabrication of endothelial progenitor cell (EPC)-seeded intravascular stent devices and in vitro endothelialization on hybrid vascular tissue. Biomaterials. 2003;24(13):2295-302.

27. Ranjan AK, Kumar U, Hardikar AA, Poddar P, Nair PD, Hardikar AA. Human blood vessel-derived endothelial progenitors for endothelialization of small diameter vascular prosthesis. PLoS ONE. 2009;4(11):e7718.

28. Abou-Saleh H, Hachem A, Yacoub D, Gillis MA, Merhi Y. Endothelial progenitor cells inhibit platelet function in a P-selectin-dependent manner. J Transl Med. 2015;13:142.

29. Ingram DA, Mead LE, Tanaka H, Meade V, Fenoglio A, Mortell K, Pollok K, Ferkowicz MJ, Gilley D, Yoder MC. Identification of a novel hierarchy of endothelial progenitor cells using human peripheral and umbilical cord blood. Blood. 2004;104(9):2752-60.

30. Prater DN, Case J, Ingram DA, Yoder MC. Working hypothesis to redefine endothelial progenitor cells. Leukemia. 2007;21(6):1141-9.

31. Gulati R, Jevremovic D, Peterson TE, Chatterjee $S$, Shah V, Vile RG, Simari RD. Diverse origin and function of cells with endothelial phenotype obtained from adult human blood. Circ Res. 2003;93(11):1023-5.

32. Yoder MC. Endothelial progenitor cell: a blood cell by many other names may serve similar functions. J Mol Med. 2013;91(3):285-95.

33. Resch T, Pircher A, Kahler CM, Pratschke J, Hilbe W. Endothelial progenitor cells: current issues on characterization and challenging clinical applications. Stem Cell Rev. 2012;8(3):926-39.

34. Yang N, Li D, Jiao P, Chen B, Yao S, Sang H, Yang M, Han J, Zhang Y, Qin S. The characteristics of endothelial progenitor cells derived from mononuclear cells of rat bone marrow in different culture conditions. Cytotechnology. 2011;63(3):217-26.

35. Lin RZ, Moreno-Luna R, Li D, Jaminet SC, Greene AK, Melero-Martin JM Human endothelial colony-forming cells serve as trophic mediators for mesenchymal stem cell engraftment via paracrine signaling. Proc Natl Acad Sci. 2014;111(28):10137-42.

36. Mead LE, Prater D, Yoder MC, Ingram DA. Isolation and characterization of endothelial progenitor cells from human blood. Curr Protoc Stem Cell Biol. 2008; Chapter 2:Unit 2C 1.
37. Zhang Y, Ingram DA, Murphy MP, Saadatzadeh MR, Mead LE, Prater DN, Rehman J. Release of proinflammatory mediators and expression of proinflammatory adhesion molecules by endothelial progenitor cells. Am J Physiol Heart Circ Physiol. 2009;296(5):H1675-82.

38. Stroncek JD, Grant BS, Brown MA, Povsic TJ, Truskey GA, Reichert WM. Comparison of endothelial cell phenotypic markers of late-outgrowth endothelial progenitor cells isolated from patients with coronary artery disease and healthy volunteers. Tissue Eng Part A. 2009;15(11):3473-86.

39. Yamamoto K, Takahashi T, Asahara T, Ohura N, Sokabe T, Kamiya A, Ando J. Proliferation, differentiation, and tube formation by endothelial progenitor cells in response to shear stress. J Appl Physiol. 2003;95(5):2081-8.

40. Yoon CH, Hur J, Park KW, Kim JH, Lee CS, Oh IY, Kim TY, Cho HJ, Kang HJ, Chae $\mathrm{H}$, et al. Synergistic neovascularization by mixed transplantation of early endothelial progenitor cells and late outgrowth endothelial cells: the role of angiogenic cytokines and matrix metalloproteinases. Circulation. 2005;112(11):1618-27.

41. Krenning $G$, van der Strate BW, Schipper M, van Seijen XJ, Fernandes BC, van Luyn MJ, Harmsen MC. CD34 + cells augment endothelial cell differentiation of CD14 + endothelial progenitor cells in vitro. J Cell Mol Med. 2009;13(8B):2521-33.

42. Cheng CC, Chang SJ, Chueh YN, Huang TS, Huang PH, Cheng SM, Tsai TN, Chen JW, Wang HW. Distinct angiogenesis roles and surface markers of early and late endothelial progenitor cells revealed by functional group analyses. BMC Genom. 2013;14:182.

43. Langer HF, May AE, Vestweber D, De Boer HC, Hatzopoulos AK, Gawaz M. Platelet-induced differentiation of endothelial progenitor cells. Semin Thromb Hemost. 2007;33(2):136-44.

44. Mitchell JA, Ali F, Bailey L, Moreno L, Harrington LS. Role of nitric oxide and prostacyclin as vasoactive hormones released by the endothelium. Exp Physiol. 2008;93(1):141-7.

\section{Submit your next manuscript to BioMed Central and take full advantage of:}

- Convenient online submission

- Thorough peer review

- No space constraints or color figure charges

- Immediate publication on acceptance

- Inclusion in PubMed, CAS, Scopus and Google Scholar

- Research which is freely available for redistribution

Submit your manuscript at

www.biomedcentral.com/submit

C Biomed Central 